\title{
Estimation of genetic parameters and breeding values for feed intake and energy balance using pedigree relationships or single-step genomic evaluation in Holstein Friesian cows
}

\author{
I. Harder, ${ }^{1 *}$ ๑ E. Stamer, ${ }^{2}$ W. Junge,${ }^{1}$ and G. Thaller $^{1}$ \\ ${ }^{1}$ Institute of Animal Breeding and Husbandry, Christian-Albrechts-University, D-24098 Kiel, Germany \\ ${ }^{2}$ TiDa Tier und Daten GmbH, D-24259 Westensee/Brux, Germany
}

\begin{abstract}
At the beginning of lactation, high-performing dairy cows often experience a severe energy deficit, which in turn is associated with metabolic stress. Increasing feed intake (FI) or reducing the energy deficit during this period could improve the metabolic stability and thus the health of the animals. Genomic selection for the first time enables the inclusion of this hard-to-measure trait in breeding programs. The objective of the current study was the estimation of genetic parameters and genomic breeding values for FI and energy balance (EB). For this purpose, 1,374 Holstein Friesian (HF) dairy cows from 8 German research farms were phenotyped with standardized FI data protocols. After data editing, phenotypic data of HF comprised a total of 40,012 average weekly FI records with a mean of $21.8 \pm 4.3$ $\mathrm{kg} / \mathrm{d}$. For EB 33,376 average weekly records were available with a mean of $3.20 \pm 29.4 \mathrm{MJ}$ of $\mathrm{NE}_{\mathrm{L}} / \mathrm{d}$. With the Illumina Bovine SNP50 BeadChip (Illumina Inc., San Diego, CA) 1,128 of phenotyped cows were genotyped. Thirty-five female candidates of the HF population were genotyped but not phenotyped. Pedigree information contained sires and dams 4 generations back. The random regression animal model included the fixed effects of herd test week (alternatively, herd group test week), parity, and stage of lactation, modeled by the function according to Ali and Schaeffer (1987). For both the random permanent environmental effect across lactations and the random additive genetic effect, third-order Legendre polynomials were chosen. Additionally, a random permanent environmental cow effect within lactation was included. Analyses for heritabilities, genetic correlations between different lactation stages, and breeding values were estimated using, respectively, pedigree relationships and single-step genomic evaluation, carried out with the DMU software package (Madsen et
\end{abstract}

Received April 24, 2019.

Accepted October 10, 2019

*Corresponding author: iharder@tierzucht.uni-kiel.de al., 2013). This allowed for comparison of conventional reliabilities with genomic-assisted reliabilities based on real data, to evaluate the gain of genotyping. Heritability estimates ranged between 0.12 and 0.50 for FI, and 0.15 and 0.48 for $\mathrm{EB}$, and increased toward the end of lactation. Genetic correlations were weak between early and late lactation, with a value of 0.05 for FI and negative with a value of -0.05 for EB. Reliabilities for genomic values of cows for FI and EB ranged between 0.33 and 0.61 , and 0.27 and 0.47 , respectively. For the genotyped cows without phenotypes, the inclusion of genomic relationship leads to an increase of the average reliability of the breeding value for FI by nearly $9 \%$ and for EB by $4 \%$. The results show the possibility of combining pedigree, genotypes, and phenotypes for increasing FI or EB to reduce health and reproductive problems, especially at the beginning of lactation. Nevertheless, the reference population needs to be extended to reach higher breeding value reliabilities.

Key words: feed intake, energy balance, cow genomic data, single-step

\section{INTRODUCTION}

Cows have long been bred for high milk yield (MY), but the considerable increase in milk production has been accompanied by a higher occurrence of health and fertility problems (Mäntysaari et al., 2012). In this context, different aspects need to be considered. On the one hand, feed costs constitute the major expense in dairy production, for which reason it is economically important to improve feed efficiency (Wallén et al., 2017). However, because higher efficiency and increased milk production are accompanied by a pronounced energy deficit, this can lead to metabolic stress and health problems (Mäntysaari et al., 2012; Spurlock et al., 2012).

Especially at the beginning of lactation, MY increases faster compared with feed intake (FI; Spurlock et al., 2012). When energy expenditures exceed intake, dairy cows experience energy deficits with eventu- 
ally high intensity and long duration (de Vries and Veerkamp, 2000; von Leesen et al., 2014). Moreover, the pronounced negative energy balance (EB) is associated with metabolic diseases such as acidosis, ketosis, and milk fever (Randhawa et al., 2014). Metabolic imbalances, reproductive problems, and other health issues are the limiting factors for reproductive life span (Rauw et al., 1998; Heringstad et al., 2000; Reist et al., 2002), and producers must be aware of the potential correlated changes that might influence fitness and welfare of dairy cows (Oltenacu and Broom, 2010). These antagonistic aspects are well known, and in this context, the traits FI and EB have been suggested as selection traits to improve fitness (Spurlock et al., 2012). Increased FI can enable an adequate energy supply, resulting in improved health, metabolic stability, and sustainable means of increasing farm profitability (Coffey et al., 2002).

So far, breeding for FI using conventional breeding values has been hampered due to an insufficient data basis, caused by the difficulty and cost of measuring the trait (de Haas et al., 2015). It is primarily research farms that have the ability to collect individual FI data of cows. The usefulness of inclusion of FI and EB in breeding goals depends strongly on genetic parameters (Tetens et al., 2014). Sound knowledge of the genetic architecture and the reliability of the inheritance of these traits are essential. Feed intake seems to be influenced by different genes at different stages of lactation (Veerkamp and Koenen, 1999; Berry et al., 2007; Tetens et al., 2014). This means that genetic parameters such as heritabilities and genetic correlations between different lactation stages vary across lactation. Therefore, different stages of lactation need to be analyzed as different but correlated traits.

Since the introduction of genomic selection (Meuwissen et al., 2001), integration of the hard-to-measure traits FI and EB into the breeding goals of dairy livestock populations seems to have become more efficient. Already in 2011, shortly after the implementation of genomic selection in dairy breeding, an international project (gDMI) has been initiated and realized, to establish a sufficiently precise breeding value estimation for the FI trait (Veerkamp et al., 2013; Berry et al., 2014; de Haas et al., 2015).

In the current study, the single-step method is used for genomic evaluations (Aguilar et al., 2010; Christensen and Lund, 2010). Through application of this method, genotypic, pedigree, and phenotypic information are combined, and all available information can be used simultaneously (Legarra et al., 2014). The singlestep method provides the best comprehensive option for genomic evaluation and is considered to be the most effective approach to generate genomic breeding values with accurate results (Aguilar et al., 2010; Christensen and Lund, 2010; Přibyl et al., 2015). Achieving high accuracy is important because the reliability of predicted genomic breeding values determines the benefit from genomic selection (Meuwissen et al., 2001; Edriss et al., 2013). Besides the size of the reference population, accuracy depends on heritability and genetic relationship (Goddard and Hayes, 2009).

The aim of this study is the implementation of the single-step evaluation for the Holstein Friesian breed (HF), using data from 8 dairy research farms located across Germany, for the FI and EB traits. These data are used to analyze heritabilities, genetic correlations between different lactation stages, and breeding values. We compared FI and EB between pedigree-based and single-step estimation runs. Furthermore, we compared realized breeding value reliabilities for cows and sires with or without phenotypic information.

\section{MATERIALS AND METHODS}

\section{Phenotypic Data}

For the estimation of the genomic and conventional breeding values, 1,341 $\mathrm{HF}$ for $\mathrm{FI}$ and 1,322 for EB, with weekly averaged values, were available (Table 1 ). Energy intake represents net energy for lactation $\left(\mathrm{NE}_{\mathrm{L}}\right)$ and was computed by summing the energy amounts of eaten partial or total mixed rations and concentrates. For the calculation of EB we used energy intake, milk energy, maintenance costs, gestation stage, and body weight at the beginning of lactation, as parameter of growth of first-lactation cows. Individual feed intake was recorded in 12 German research farms via feeding troughs equipped with a weighing unit and automatic cow identification. Cows were fed ad libitum. The target value for concentrates was predetermined by the project optiKuh, at $250 \mathrm{~g} / \mathrm{kg}$ of ECM. Data were edited and summarized within farms. Due to different frequencies of measurement (e.g., daily FI and weekly milk ingredients) traits were averaged within calendar week. The considered lactation period was defined from the 1st to the 350th day. Observations outside of 4 standard deviations were excluded from further analyses. The resulting means for FI, MY, and EB were 21.8 $\mathrm{kg}, 35.5 \mathrm{~kg}$, and $3.20 \mathrm{MJ}$ of $\mathrm{NE}_{\mathrm{L}}$.

Available pedigree information for cows is traced 4 generations back. Detailed information is given in Harder et al. (2019).

\section{Genotypic Data}

Genotypic data consisted of 1,895 cows in total, sires and sons of sires, genotyped with the Illumina Bovine 
Table 1. Descriptive statistics for weekly records of the feed intake, energy balance, and milk yield traits

\begin{tabular}{lcccc}
\hline Trait & No. of cows & No. of parities & No. of observations & Mean \\
\hline Feed intake (kg of DM) & 1,341 & 1,928 & 40,012 & 21.8 \\
Energy balance (MJ of $\mathrm{NE}_{\mathrm{L}}$ ) & 1,322 & 1,865 & 33,376 & 4.25 \\
Milk yield (kg) & 1,338 & 1,917 & 39,838 & 3.20 \\
\hline
\end{tabular}

SNP50 BeadChip (50K, Illumina Inc., San Diego, CA). Three data panels were used for the genetic analyses. The main panel consisted of 1,163 cows genotyped with the Illumina Bovine SNP50 BeadChip versions v2_C and v3_A1. Of these cows 1,128 were phenotyped. For another $35 \mathrm{HF}$, no phenotypic information was available. In the second panel, 491 sires and grandsires of cows were genotyped with chip versions A and v2_C. As well, 241 sons of these sires (fathers) were genotyped with versions A and v2 (Table 2). For final evaluation, a joint SNP set was created, containing all common SNP of the 3 chip versions $(\mathrm{n}=49,184)$.

To ensure sufficient genotypic data quality, SNP and individuals with call rates lower than $95 \%$ and mean GenCall score (GC score) lower than 0.6 (Edriss et al., 2013) were excluded. After quality control, the final SNP data set contained 1,828 animals (1,163 cows, 448 sires, 217 grandsires) and 45,373 common SNP.

Genotypes were coded as 0 for missing nucleobase information, 1 for adenine, 2 for cytosine, 3 for guanine, and 4 for thymine. Using the software package Gmatrix (Madsen et al., 2013), the genomic relationship matrix was calculated using the method described by VanRaden (2008). We selected a minor allele frequency of $1 \%$, representing the default justification of G-matrix. The SAS procedure INBREED was used to enable comparison between the pedigree-based and genomic relationships (SAS, 2012).

\section{Statistical Model}

Model evaluations for FI and EB were conducted in the previous study of Harder et al. (2019). Based upon the results of that study, the general lactation curves were modeled within lactation number using the function described by Ali and Schaeffer (1987). Random regression coefficients for permanent cow effects and additive genetic effects were modeled using third-degree Legendre polynomials (LP3; Brotherstone et al., 2000). Additionally a mean permanent environmental effect of the cow within lactation was considered. A finer modeling of this effect by a Legendre polynomial could not be realized, due to missing convergence. Furthermore, the model includes the fixed effects lactation number and herd test week. In case of significant feeding group effects, herd test week was replaced by herd group test week, which had to contain at least 2 observations. This resulted in the following linear random regression model for the estimation of genetic parameters:

$$
\begin{aligned}
& \mathrm{y}_{\mathrm{ijklm}}=\mu+\mathrm{HTW}_{\mathrm{i}}+\mathrm{LNO}_{\mathrm{j}}+\sum_{\mathrm{n}=1}^{4} C_{\mathrm{jn}} \mathrm{as}_{\mathrm{jn}} \\
& +\sum_{\mathrm{n}=1}^{4} \mathrm{p}_{\mathrm{kn}} \mathrm{lp}_{\mathrm{kn}}+\mathrm{p}_{\mathrm{l}}+\sum_{\mathrm{n}=1}^{4} \mathrm{a}_{\mathrm{kn}} \mathrm{lp}_{\mathrm{kn}}+\mathrm{e}_{\mathrm{ijklm}},
\end{aligned}
$$

where $y_{\mathrm{ijklm}}$ is the weekly trait observation; $\mu$ is the overall intercept; $\mathrm{HTW}_{\mathrm{i}}$ is the fixed effect of the ith herd (group) test week; $\mathrm{LNO}_{\mathrm{j}}$ is the fixed effect of the jth lactation class $(\mathrm{j}=1, \ldots, 4)$, with class 4 including the fourth and higher lactations; $\mathrm{C}_{\mathrm{jn}}$ is the nth fixed regression coefficient within lactation class $\mathrm{j} ; \mathrm{as}_{\mathrm{jn}}$ is the nth term of the Ali and Schaeffer function for DIM within lactation class $\mathrm{j} ; \mathrm{p}_{\mathrm{kn}}$ is the nth random regression coefficient of the permanent environmental effect of the kth cow; $l p_{\mathrm{kn}}$ is the nth term of the LP3 for DIM

\begin{tabular}{|c|c|c|c|c|c|}
\hline \multirow[b]{2}{*}{ Chip version ${ }^{1}$} & \multicolumn{4}{|c|}{ No. of animals } & \multirow[b]{2}{*}{ No. of SNP } \\
\hline & SNP & Cows & Sires/grandsires & Sons of sires & \\
\hline Illumina BovineSNP50 BeadChip_v2_C & 54,609 & 1,026 & 146 & 186 & \\
\hline Illumina BovineSNP50 BeadChip_v3_A1 & 53,218 & 137 & - & - & \\
\hline Total no. of animals & & 1,163 & 491 & 241 & \\
\hline Animal callrate $(\geq 0.95)$ & & 1,163 & 448 & 217 & \\
\hline SNP call rate $\geq 0.95$ & & & & & 45,373 \\
\hline
\end{tabular}

Table 2. Genotypic data: number of animals and SNP of raw data and after quality control

${ }^{1}$ Illumina, San Diego, CA. 
of cow $\mathrm{k} ; \mathrm{p}_{\mathrm{l}}$ is the random effect of the lth combination between permanent environmental cow effect and lactation $(1, \ldots, 11) ; a_{\mathrm{kn}}$ is the $\mathrm{nth}$ random regression coefficient of the additive genetic effect of the kth cow; and $\mathrm{e}_{\mathrm{ijk} k \mathrm{~m}}$ is the random residual effect.

In matrix notation, the random regression model can be written thus:

$$
\mathbf{y}=\mathbf{X b}+\mathbf{Z}_{1} \mathbf{p}+\mathbf{Z}_{2} \mathbf{l}+\mathbf{Z}_{3} \mathbf{a}+\mathbf{e}
$$

where $\mathbf{b}=$ unknown parameters for fixed effects and fixed regression coefficients, $\mathbf{p}=$ random regression coefficients for permanent environmental cow effects across lactations, $\mathbf{l}=$ vector of permanent environmental cow effects within lactation, $\mathbf{a}=$ random regression coefficients for additive genetic cow effects, $\mathbf{e}=$ vector of temporary environmental (residual) effects, and $\mathbf{X}$, $\mathbf{Z}_{1}, \mathbf{Z}_{2}$, and $\mathbf{Z}_{3}$ are the corresponding incidence and covariate matrices.

The mixed model equations are represented as follows:

$$
\begin{aligned}
& \left(\begin{array}{cccc}
\mathbf{X}^{\prime} \mathbf{X} & \mathbf{X}^{\prime} \mathbf{Z}_{1} & \mathbf{X}^{\prime} \mathbf{Z}_{2} & \mathbf{X}^{\prime} \mathbf{Z}_{3} \\
\mathbf{Z}_{1}^{\prime} \mathbf{X} & \mathbf{Z}_{1}^{\prime} \mathbf{Z}_{1}+\mathbf{I} \otimes \mathbf{\alpha}_{1} & \mathbf{Z}_{1}^{\prime} \mathbf{Z}_{2} & \mathbf{Z}_{1}^{\prime} \mathbf{Z}_{3} \\
\mathbf{Z}_{2}^{\prime} \mathbf{X} & \mathbf{Z}_{2}^{\prime} \mathbf{Z}_{1} & \mathbf{Z}_{2}^{\prime} \mathbf{Z}_{2}+\mathbf{I} \mathbf{\alpha}_{2} & \mathbf{Z}_{2}^{\prime} \mathbf{Z}_{3} \\
\mathbf{Z}_{3}^{\prime} \mathbf{X} & \mathbf{Z}_{3}^{\prime} \mathbf{Z}_{1} & \mathbf{Z}_{3}^{\prime} \mathbf{Z}_{2} & \mathbf{Z}_{3}^{\prime} \mathbf{Z}_{3}+\mathbf{H}^{-1} \otimes \mathbf{\alpha}_{3}
\end{array}\right)\left(\begin{array}{l}
\mathbf{b} \\
\mathbf{p} \\
\mathbf{l} \\
\mathbf{a}
\end{array}\right) \\
& =\left(\begin{array}{l}
\mathbf{X}^{\prime} \mathbf{Y} \\
\mathbf{Z}_{1}^{\prime} \mathbf{Y} \\
\mathbf{Z}_{2}^{\prime} \mathbf{Y} \\
\mathbf{Z}_{3}^{\prime} \mathbf{Y}
\end{array}\right),
\end{aligned}
$$

where $\mathbf{H}$ is the combined numerator and genomic relationship matrix; $\mathbf{I}$ is an identity matrix, $\mathbf{\alpha}_{1}=\mathbf{P}^{-1} \sigma_{e}^{2}$, $\mathbf{\alpha}_{2}=\sigma_{e}^{2} / \sigma_{l}^{2}, \mathbf{\alpha}_{3}=\mathbf{G}^{-1} \sigma_{e}^{2}, \mathbf{G}$ is the variance-covariance matrix of the additive genetic random regression coefficients; $\mathbf{P}$ is the variance-covariance matrix of the permanent environmental random regression coefficients across lactations; $\sigma_{l}^{2}$ is the permanent environmental variance within lactation.

Variance components, heritabilities, genetic correlations between lactation stages, and breeding values for weekly FI and EB were estimated in 2 ways, using DMU software (Madsen et al., 2013). First, a genetic evaluation was carried out using phenotypes and the pedigree relationship matrix. Second, the single-step method was applied, combining genotype, pedigree, and phenotypic information. The pedigree relationship matrix was augmented by genomic relationship, so the inverse of the resulting matrix $\mathbf{H}$ can be seen as a modification of regular pedigree relationships to accom- modate genomic relationships. Any formulation using inverse relationship $\mathbf{A}^{-1}$ can use $\mathbf{H}^{-1}$ instead (Legarra et al., 2009).

Based on the procedures outlined in Aguilar et al. (2010) and Christensen and Lund (2010), the inverse of the matrix $\mathbf{H}$ can be written, according to Legarra et al. (2014), as

$$
\mathbf{H}^{-1}=\mathbf{A}^{-1}+\left\{\begin{array}{lc}
\mathbf{0} & \mathbf{0} \\
\mathbf{0} & {\left[(\mathbf{1}-\mathbf{w}) \mathbf{G}+\mathbf{w A}_{22}\right]^{-1}-\mathbf{A}_{22}^{-1}}
\end{array}\right\},
$$

where $\mathbf{A}^{-1}$ is the inverse of the pedigree relationship matrix for all animals, $\mathbf{G}$ is the genomic relationship matrix for genotyped animals, and $\mathbf{A}_{22}^{-1}$ represents the inverse of the pedigree relationship matrix for all genotyped animals. Previous studies have investigated the use of weight ( $\mathrm{w}$ ) to avoid convergence problems and bias (Guarini et al., 2018). In this study, a weight of $5 \%$ for both traits FI and EB was applied. Estimated (co) variances and LP3 coefficients were used for both calculation of heritabilities for all considered DIM and calculation of genetic correlations between selected lactation stages. Finally, reliabilities of mean breeding values were computed as follows:

$$
r^{2}=1-\frac{\mathrm{PEV}}{\sigma_{a}^{2}}
$$

where PEV is the predicted error variance of the intercept for the estimated cow-specific LP3 function and $\sigma_{a}^{2}$ is the additive genetic variance. The intercept represents the mean breeding value.

For this study, different data sets were prepared to estimate genetic parameters and breeding values for FI and EB. The first data set (1) consists of all cows of the optiKuh training population with only pedigree relationship (Data_1). For data set 2, the first data set was augmented by genomic information of the cows (Data_2). For the third (3), Data_2 was augmented by genomic information of the sires and dam sires (Data_3). In the final set (4), genotyped sons of the sires are included as well (Data_4).

\section{RESULTS}

To ensure a high-quality SNP, the signal strength of every SNP GC score was measured. The quality control threshold (indicated in Figure 1 by the vertical line running the whole height of the graph) was set at 0.6 , so every SNP with a mean GC score lower than 0.6 
was excluded from further analysis. Overall 7,453 SNP $(14.64 \%)$ lay below this threshold and were discarded.

The pedigree check step for data quality control ensures the identification of every animal with an incorrectly recorded pedigree, a misidentified cow, an incorrect cow sample, or a mistake in breed category. In total, 14 animals were excluded. This step also allows the checking of full-sibs and half-sibs. Figure 2 illustrates the relatedness of cows through the comparison of pedigree relationship coefficients and marker relationship coefficients. Spots are expected to be located along the diagonal, in the area around 0 (unrelated), 0.25 (half-sibs), 0.5 (full-sibs), or 1 (related to itself). A few outliers in the areas around 0 and 0.3 may constitute inconsistencies in, first, the pedigree, under assumption of correct genomic coefficients, or, second, blood samples that were assigned wrongly, under the assumption of correct pedigree information. The negative marker relationships are due to the G-matrix method, which uses the allele frequencies in the base population, but these frequencies are unknown (VanRaden, 2008). Therefore, the G-matrix was calculated by using the allele frequencies of the available population, which resulted in a partly negative marker relationship.

Figure 3 depicts heritability estimates of FI and EB across lactation, distinguished between Data_1 and Data_2. Heritabilities of FI ranged from 0.12 to 0.50 , with the lowest values in early lactation, which increased slightly from lactation DIM 150 onward, with the highest values found at the end of lactation. Similar to this pattern, the heritability estimates for EB ranged from 0.15 to 0.48 . In general, estimated heritabilities of both traits were lower at the beginning of lactation but increased until the end of the considered lactation. The heritability estimates derived from Data_2 were rather similar at the beginning of lactation but had a lower trajectory, so the heritability shifted around 100 DIM, and the conventional heritability was higher at the end.

Genetic correlations of FI and EB between 12 selected, equidistant DIM are presented in Table 3 (Data_1) and Table 4 (Data_2). For FI, values ranged from 0.05 to 1.00 in Data_1 and from 0.05 to 0.99 in Data_2. In general, estimated genetic correlations were slightly higher in Data_2 (Table 4). Genetic correlations for

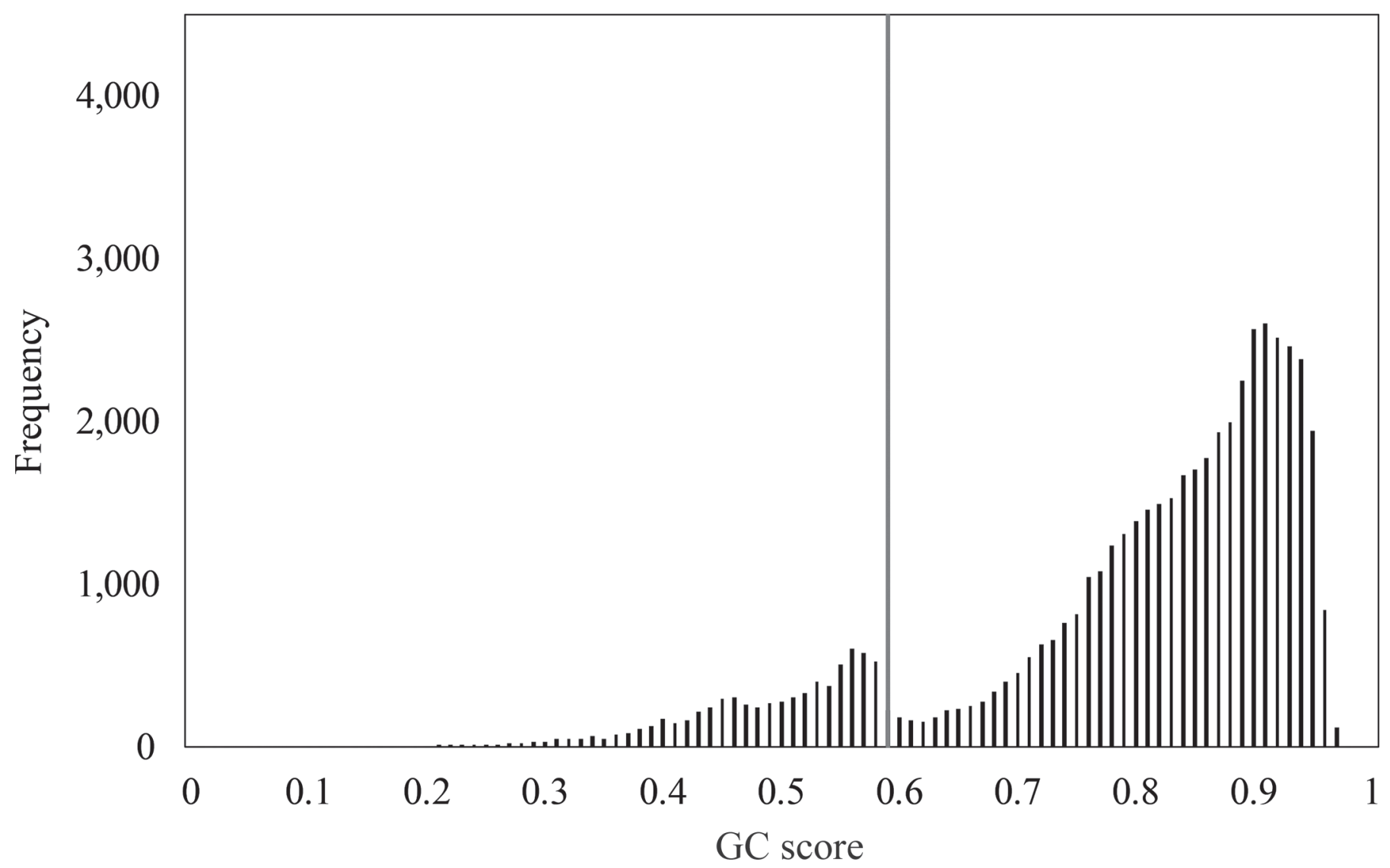

Figure 1. Frequency distribution of the mean GenCall score (GC score). Quality control threshold set at 0.6, indicated by vertical line in graph. 


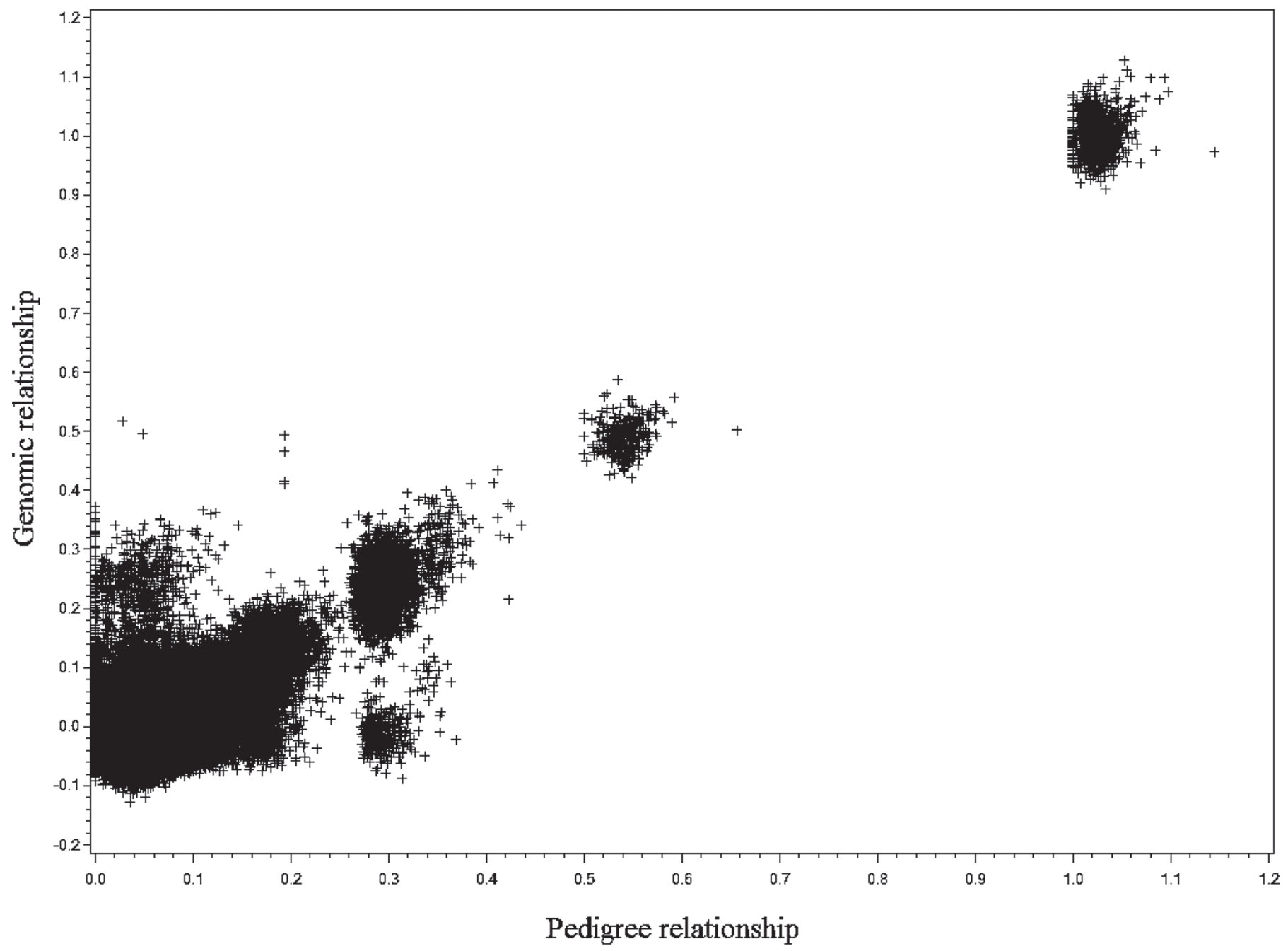

Figure 2. Comparison of the relationship coefficients between pedigree relationship matrix and genomic relationship matrix.

EB in Data_1 were all positive and ranged from 0.00 to 0.97 , whereas values in Data_2 are positive until 310 DIM and then turn into the negative range.

In general, genetic correlations between contiguous DIM are high and decrease with increasing DIM intervals. Both FI and EB show the same trajectory in the course of lactation. Estimates from early and midlactation are in the middle range, whereas correlations between early and late lactation are low. One value in Data_2 for EB is even negative.

The realized reliabilities for mean breeding values of the cows for FI are shown in Figure 4. The reliabilities increase with rising numbers of FI weekly records. Up to 40-week averages, the reliability for Data $\_2$ was higher than for Data_1. This indicates, that in the current study, the less data available, the higher the benefit of using single-step data, with respect to reliabilities of breeding values. However, the more data available for computations, the higher the reliabilities of the breeding values with Data_1. The highest reliabilities for Data_1 were 0.62 and, for Data_2, 0.61 .

As expected, the differences between the 4 data sets within the single-step are marginal, and added genomic information of sires and sons of sires did not significantly improve reliabilities in this study. For the 35 cows without phenotypic but with genotypic information, single-step reliability of 0.23 could be realized, which is 0.09 higher than the pedigree-based reliability of 0.14. Similar to FI, the reliabilities of EB breeding values are higher using single-step for cows with fewer (up to 20) observations, but this changes with an increasing number of observations per cow. In general, the observed reliabilities for FI are slightly higher than for EB (maximum value for FI of 0.62 and for EB of 0.60 ; Figure 5). For the 1,163 genotyped cows, FI breeding values of pedigree-based results (Data_1) are 
Table 3. Genetic correlations of Data_1 set (consisting of all cows of the optiKuh training population with pedigree relationships only) for feed intake (above the diagonal) and energy balance (below the diagonal) traits between different DIM

\begin{tabular}{lccccccccccccc}
\hline DIM & 10 & 40 & 70 & 100 & 130 & 160 & 190 & 220 & 250 & 280 & 310 & 340 \\
\hline 10 & 0.82 & 0.80 & 0.52 & 0.35 & 0.24 & 0.17 & 0.13 & 0.10 & 0.09 & 0.08 & 0.07 & 0.05 \\
40 & 0.49 & 0.90 & 0.93 & 0.82 & 0.70 & 0.56 & 0.44 & 0.35 & 0.32 & 0.35 & 0.42 & 0.49 \\
70 & 0.26 & 0.75 & 0.96 & 0.97 & 0.89 & 0.77 & 0.63 & 0.53 & 0.50 & 0.53 & 0.62 & 0.70 \\
100 & 0.12 & 0.61 & 0.87 & 0.97 & 0.97 & 0.89 & 0.78 & 0.69 & 0.65 & 0.68 & 0.75 & 0.80 \\
130 & 0.04 & 0.47 & 0.74 & 0.88 & 0.97 & 0.97 & 0.90 & 0.83 & 0.80 & 0.81 & 0.84 & 0.84 \\
160 & 0.00 & 0.34 & 0.59 & 0.75 & 0.88 & 0.97 & 0.98 & 0.94 & 0.91 & 0.91 & 0.90 & 0.83 \\
190 & 0.00 & 0.25 & 0.46 & 0.63 & 0.78 & 0.90 & 0.98 & & 0.98 & 0.96 & 0.92 & 0.80 \\
220 & 0.02 & 0.22 & 0.40 & 0.55 & 0.70 & 0.84 & 0.94 & 0.99 & & 0.98 & 0.92 & 0.78 \\
250 & 0.04 & 0.26 & 0.43 & 0.56 & 0.69 & 0.80 & 0.89 & 0.94 & 0.98 & 0.94 & 0.80 \\
280 & 0.06 & 0.35 & 0.52 & 0.62 & 0.69 & 0.74 & 0.77 & 0.80 & 0.86 & 0.95 & 0.97 & 0.87 \\
310 & 0.05 & 0.42 & 0.60 & 0.65 & 0.66 & 0.63 & 0.59 & 0.58 & 0.63 & 0.77 & 0.93 & 0.96 \\
340 & & & & & & & & & & &
\end{tabular}

contrasted with single-step estimations (Data_2). The fitted linear regression shows a coefficient of determination of $\mathrm{R}^{2}=0.86(\mathrm{r}=0.93$; Figure 6$)$.

Figures 7 and 8 show reliabilities of the FI and EB breeding values for the sires. With increasing numbers of daughters, the reliability gets higher. A sire with a maximum of 5 daughters could generate reliabilities of roughly 0.27 for FI and 0.21 for EB. Additional inclusion of genotyped sires, dam-sires, and sons led to higher reliabilities only for sires with a maximum of 10 daughters. Reliabilities increased up to $5.3 \%$ for FI and up to $3.8 \%$ for EB. For sires with more than 10

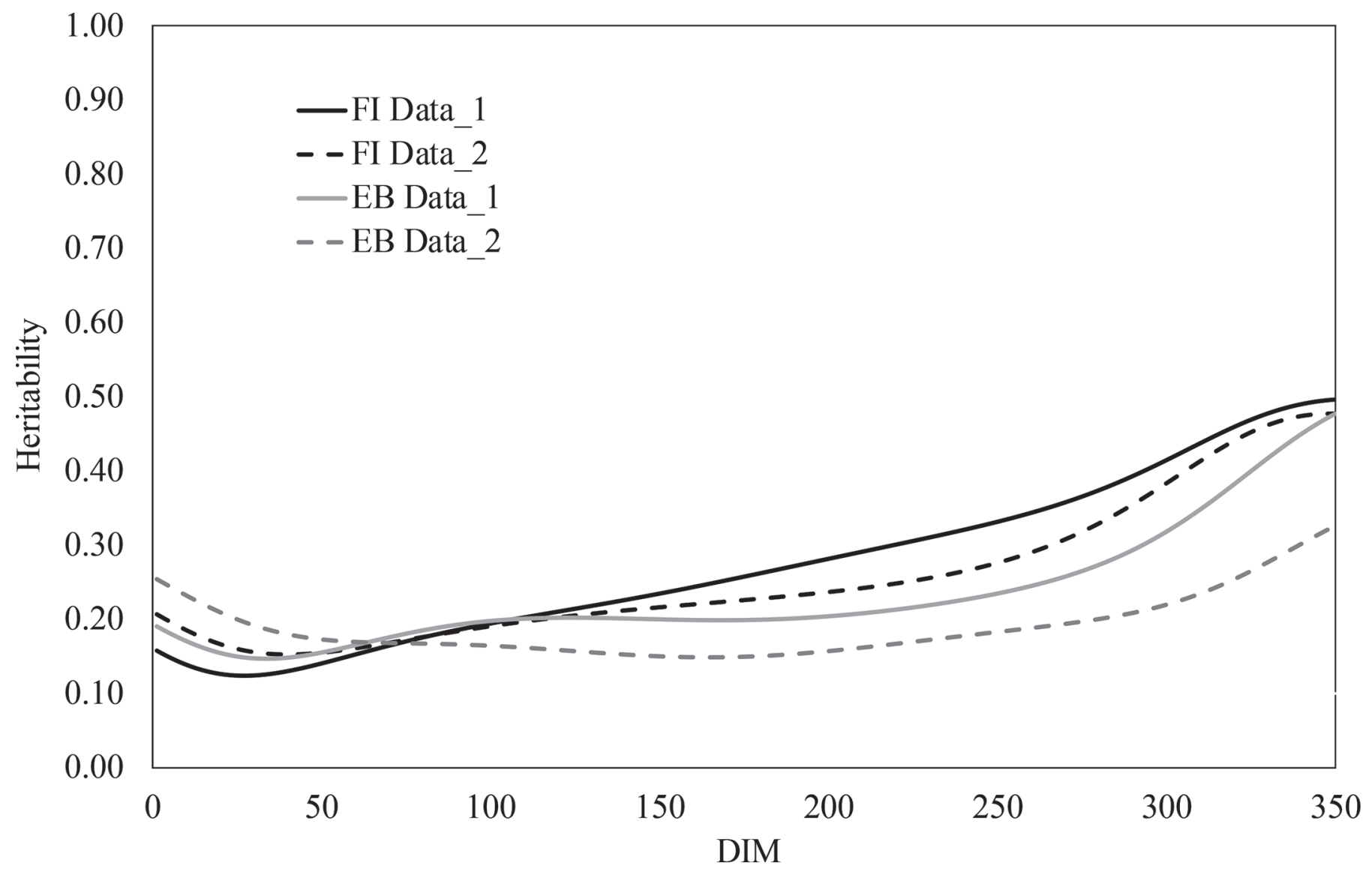

Figure 3. Heritabilities of feed intake (FI) and energy balance (EB) of Data_1 set (consisting of all cows of the optiKuh training population with pedigree relationships only) and Data_2 set (consisting of all cows of the optiKuh training population with both pedigree and genomic relationships) across the first 350 DIM. 
Table 4. Genetic correlations of Data_2 set (consisting of all cows of the optiKuh training population with both pedigree and genomic relationships) for feed intake (above the diagonal) and energy balance (below the diagonal) traits between different DIM

\begin{tabular}{lccccccccccccc}
\hline DIM & 10 & 40 & 70 & 100 & 130 & 160 & 190 & 220 & 250 & 280 & 310 \\
\hline 10 & 0.87 & 0.82 & 0.51 & 0.31 & 0.22 & 0.18 & 0.17 & 0.17 & 0.17 & 0.16 & 0.11 & 0.05 \\
40 & 0.58 & 0.90 & 0.91 & 0.78 & 0.68 & 0.51 & 0.52 & 0.47 & 0.47 & 0.49 & 0.51 & 0.50 \\
70 & 0.35 & 0.75 & 0.96 & 0.97 & 0.90 & 0.82 & 0.73 & 0.66 & 0.65 & 0.68 & 0.72 & 0.72 \\
100 & 0.22 & 0.62 & 0.86 & 0.97 & 0.98 & 0.92 & 0.85 & 0.79 & 0.77 & 0.78 & 0.80 & 0.78 \\
130 & 0.17 & 0.49 & 0.73 & 0.87 & 0.96 & 0.98 & 0.93 & 0.89 & 0.86 & 0.86 & 0.84 & 0.78 \\
160 & 0.16 & 0.38 & 0.56 & 0.70 & 0.85 & 0.96 & 0.98 & 0.96 & 0.93 & 0.91 & 0.86 & 0.75 \\
190 & 0.16 & 0.29 & 0.42 & 0.56 & 0.73 & 0.88 & 0.98 & & 0.99 & 0.99 & 0.96 & 0.86 & 0.72 \\
220 & 0.16 & 0.25 & 0.35 & 0.49 & 0.65 & 0.82 & 0.94 & 0.99 & 0.71 & 0.98 & 0.91 & 0.76 \\
250 & 0.13 & 0.25 & 0.37 & 0.50 & 0.65 & 0.79 & 0.89 & 0.94 & 0.98 & & 0.97 & 0.86 \\
280 & 0.06 & 0.26 & 0.45 & 0.57 & 0.67 & 0.75 & 0.79 & 0.81 & 0.85 & 0.94 & 0.94 \\
310 & -0.05 & 0.27 & 0.51 & 0.61 & 0.64 & 0.62 & 0.57 & 0.54 & 0.58 & 0.73 & 0.91 \\
340 & & & & & & & & & & & & & \\
\hline
\end{tabular}

daughters, genotyped ancestors in the data set had no benefit.

We contrasted the breeding values for FI and EB of all genotyped cows and genotyped sires (Figure 9 and Figure 10). The results provide an indication of the strength of the genetic relationship between FI and EB. The fitted linear regression resulted in a correlation of $0.63\left(R^{2}=0.40\right)$ for cows and $0.66\left(R^{2}=0.43\right)$ for sires.

\section{DISCUSSION}

Genomic selection enables an efficient and indispensable process (de Haas et al., 2015), and, thus, genomic selection is a possible solution to integrate such hardto-measure traits as FI and EB in the dairy cow breeding program, to improve their health and metabolic stability. Nevertheless, the success of genomic breeding

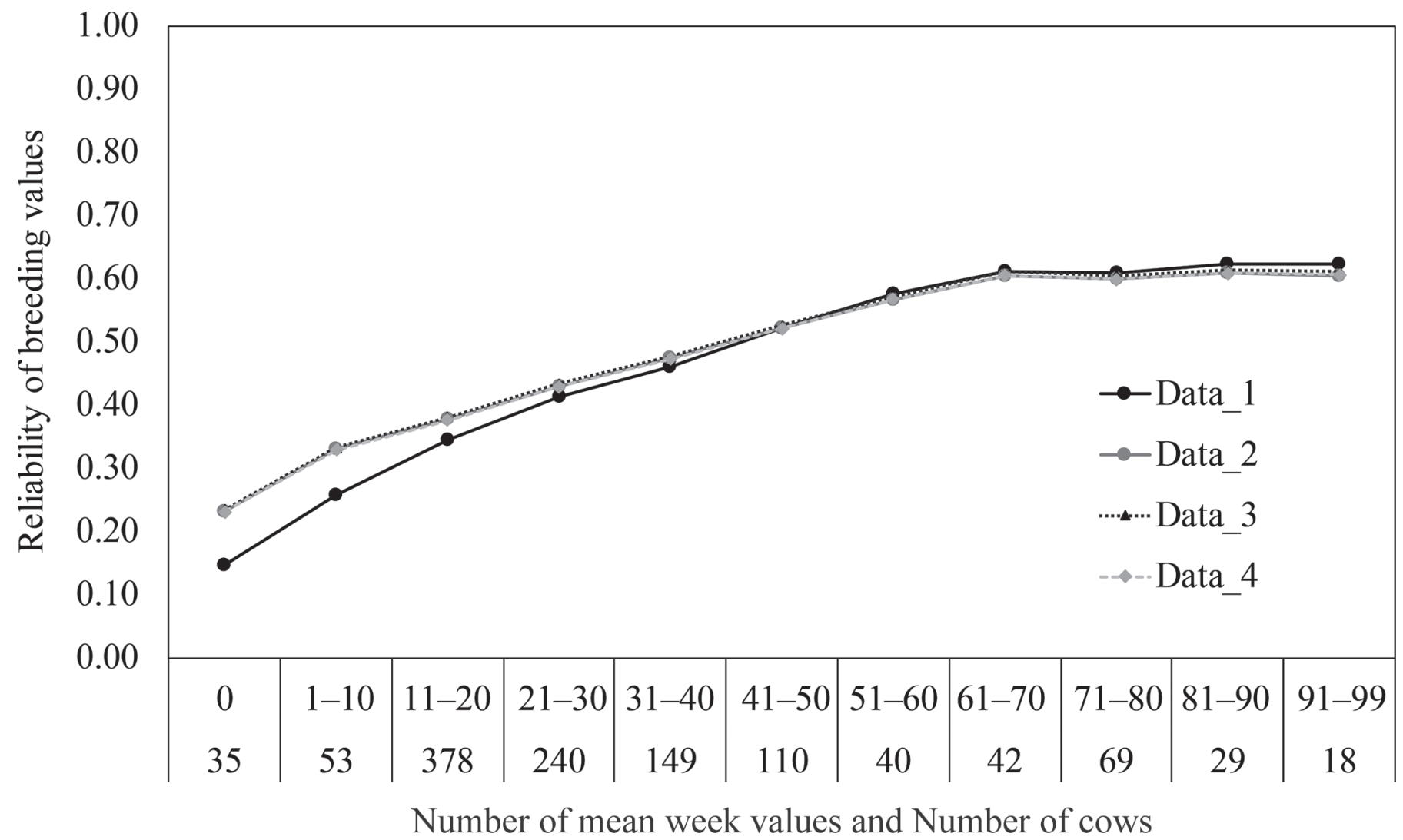

Figure 4. Realized reliabilities of breeding values for feed intake out of the 4 data sets: Data_1 (consists of all cows of the optiKuh training population with pedigree relationships only), Data_2 (consists of all cows of the optiKuh training population with both pedigree and genomic relationships), Data_3 (data set augmented with genotyped sires and dam sires), and Data_4 (data set augmented with sons of sires). On the $\mathrm{X}$ axis the numbers in the upper row show mean week values; the bottom row shows number of cows. 
evaluation and selection is strongly dependent on the recording of the trait (Daetwyler et al., 2010). Previous studies stated that very few FI and EB data were available, which causes a lack of reliable parameters due to the cost-intensive data collection (Vallimont et al., 2011; Veerkamp et al., 2012). The objective of this study was to estimate genomic breeding values for the traits FI and EB. To evaluate the importance of genotyping, cows with pedigree relationships (Data_1) and cows with pedigree and genomic relationships (Data_2) were compared, and the single-step method was used to apply this method on the optiKuh data set.

The optiKuh project provides a well-defined data set for FI and EB, with standardized measurements from 8 research farms, which represent the whole HF population across Germany. Within optiKuh, we were able to establish a homogeneous data recording across herds characterized by similar feeding and management conditions, achieving an adequate number of animals within the relatively brief period of 2 years. Furthermore, we were able to consider entire lactations of several parities. This is in contrast to other studies, where FI was mostly recorded only until DIM 150 or 180 and not throughout the lactation (Buttchereit et al., 2011; Berry and Crowley, 2013; Manzanilla Pech et al., 2014). Such an appropriate homogeneous data set, with a high number of animals with a close relationship in the actual reference population, is a precondition for achieving realistic accuracies of breeding values (Pszczola et al., 2012).

Previous results from the international FI project gDMI (Berry et al., 2007; Veerkamp et al., 2013; Berry et al., 2014) were less satisfying. The connections between populations were weak, sharing only a few common sires or grandsires. Different farming practices, as well as non-standardized rations, might be reasons for relatively low reliabilities (0.14 to 0.29 ), and the benefit of the combined data was smaller than expected (Veerkamp et al., 2013; de Haas et al., 2015).

For the use of genomic information, it is generally necessary to achieve certain quality criteria. In the current study, a threshold for the GC score at 0.6 was chosen as a compromise between quantity and quality of SNP (Cunningham et al., 2008; Pszczola et al., 2018).

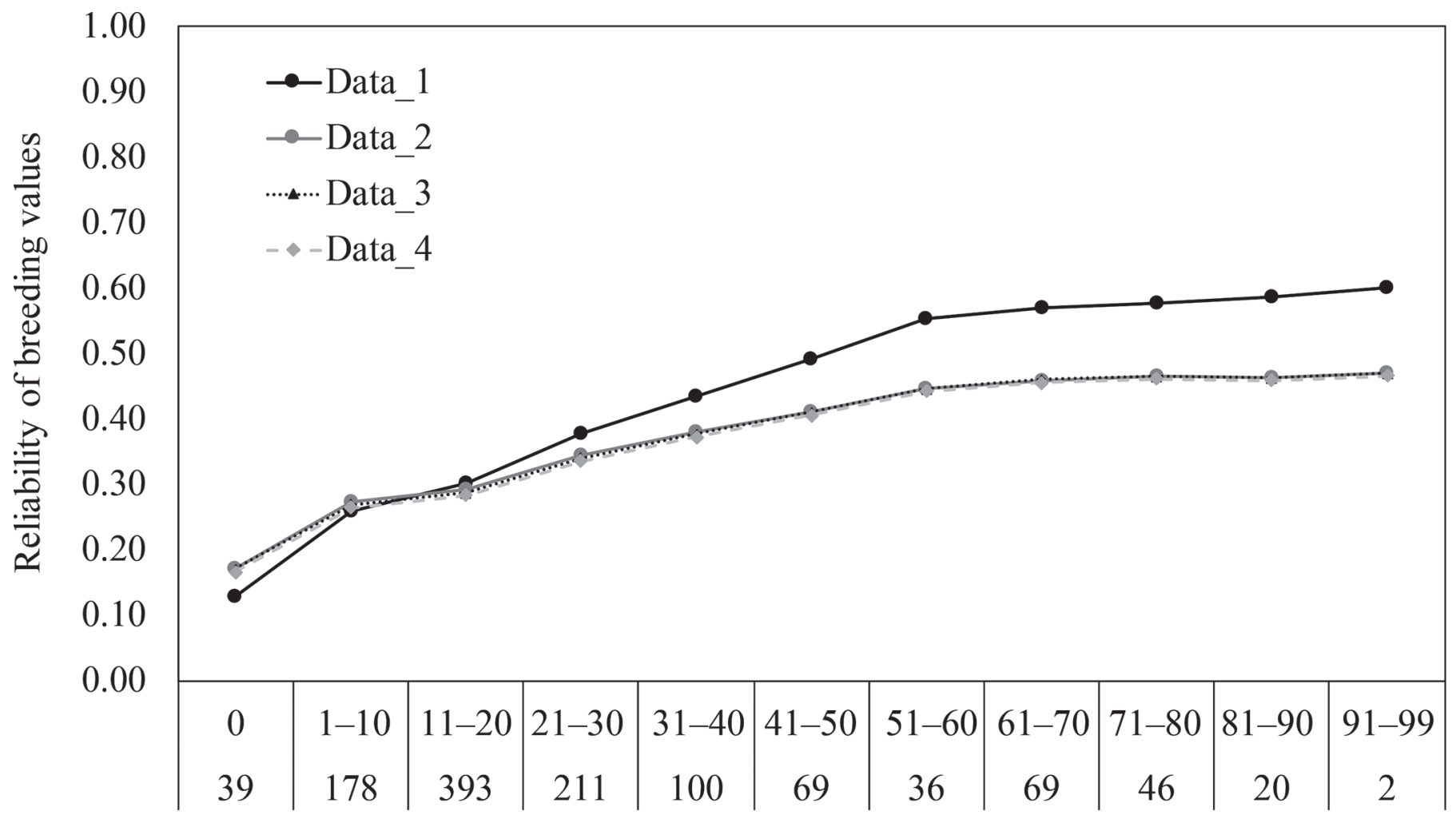

Number of mean week values and Number of cows

Figure 5. Realized reliabilities of breeding values for energy balance out of the 4 data sets: Data_1 (consists of all cows of the optiKuh training population with pedigree relationships only), Data_2 (consists of all cows of the optiKuh training population with both pedigree and genomic relationships), Data_3 (data set augmented with genotyped sires and dam sires), and Data_4 (data set augmented with sons of sires). On the $\mathrm{X}$ axis the numbers in the upper row show mean week values; the bottom row shows number of cows. 
This lies above 0.2 , a threshold Illumina Inc. (2005) and Yokoyama et al. (2010) recommend, because mean GC scores below 0.2 usually report failed genotypes.

As expected, FI and EB reliabilities of pedigreebased and single-step data increase with higher numbers of weekly records. Genomic reliabilities for FI, ranging between 0.33 and 0.61 , are high compared with the average reliabilities across validation sets in other studies, which range between 0.04 and 0.20 (Pszczola et al., 2013; Pryce et al., 2014; de Haas et al., 2015). For cows with little phenotypic information, single-step estimation generated higher reliabilities for both traits, whereas, somewhat unexpectedly, the highest reliabilities, with maximums of 0.62 , were observed in cows with only pedigree-based relationships (Data_1), if the number of weekly records exceeded 40. By contrast, Pszczola et al. (2013) observed substantially higher genomic reliabilities (0.11) compared with pedigree-based reliabilities (0.07) for FI. Manzanilla-Pech et al. (2017) also found similar results, with maximum of 0.14 for genomic and maximum of 0.09 for pedigree-based reli- abilities. Possible explanations for the deviating results in this study could be the higher heritabilities found at the end of lactation, so that cows with an entire lactation profile have more observations and benefit from these higher heritabilities in the pedigree-based alternative (see Figure 3).

In contrast, genomic estimated breeding values provide more accurate reliabilities for animals without performance data (Muir, 2007; Zambrano et al., 2015). This supports the benefits of using genomic calculations for selection at an early age, especially for hardto-measure traits. The generated reliabilities for the 35 (FI) and 39 (EB) cows without phenotypic data are 0.23 for FI and 0.17 for EB. Compared with pedigreebased relationship (Data_1), these values are above $8.6 \%$ higher for FI and $4.2 \%$ higher for EB. To improve the connectedness among animals in the reference population and increase the reliabilities of the breeding values, genotypic information of sires and dam-sires were included. Improvements were observed only for reliabilities of FI and EB breeding values in males if

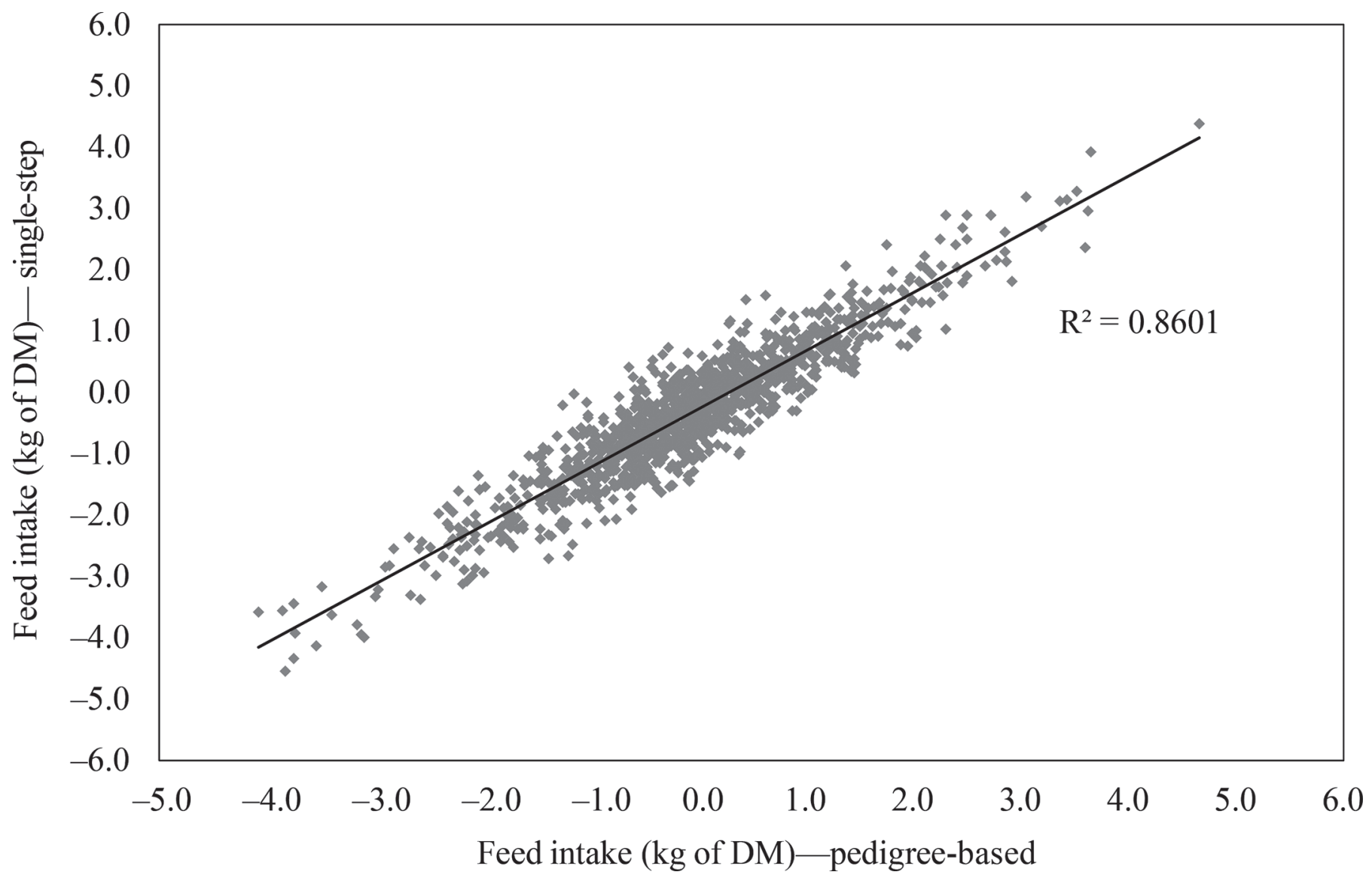

Figure 6. Scatter plot comparing mean feed intake (FI) breeding value estimations of Data_1 set (all cows of the optiKuh training population with pedigree relationships only) and Data_2 set (all cows of the optiKuh training population with both pedigree and genomic relationships). Total: 1,163 genotyped cows. 
sires had low numbers of daughters, but not for female animals.

Genetic parameters for FI have been available for a long time (Van Arendonk et al., 1991; Veerkamp, 1998), and the current results were generally in line with those of previous analyses. In this study, heritabilities of both data sets slightly decreased at the beginning of lactation but increased along DIM until the end of lactation. For the single-step method, somewhat higher heritability values were found at the beginning of lactation, but this changed around DIM 50, when conventionally estimated heritability values got higher. The very high heritability values at the end of lactation might be overestimated, especially in the case of the pedigree-based alternative. This might be due to fewer observations in total at the end of lactation and emphasizes the usefulness of genomic data. In general, genomic data better reflects realized relationships and helps to untangle the genetic and the permanent environment.
In the current study, we estimated heritabilities for the whole lactation up to 350 DIM. The resulting values are in the middle range, which is comparable to studies by Coffey et al. (2001), Liinamo et al. (2012), and Li et al. (2018). Heritability values in other investigations, in which just the first period of lactation was considered, were also in the middle range (Hüttmann et al., 2009; Spurlock et al., 2012; Krattenmacher et al., 2019).

Heritabilities as estimated in this study ranged between 0.12 and 0.50 , comparable to the results of $\mathrm{Li}$ et al. (2018), who reported values from 0.3 to 0.55 . The EB heritabilities that we found were somewhat lower and ranged between 0.15 and 0.48 . This is in agreement with Berry et al. (2007). Nevertheless, heritabilities for EB for the first 180 DIM reported by Krattenmacher et al. (2019) displayed a lower level and ranged between 0.29 and 0.49 but also increased with later DIM. In contrast, Liinamo et al. (2012) found the highest values for heritabilities in early lactation (around 0.37 ), which

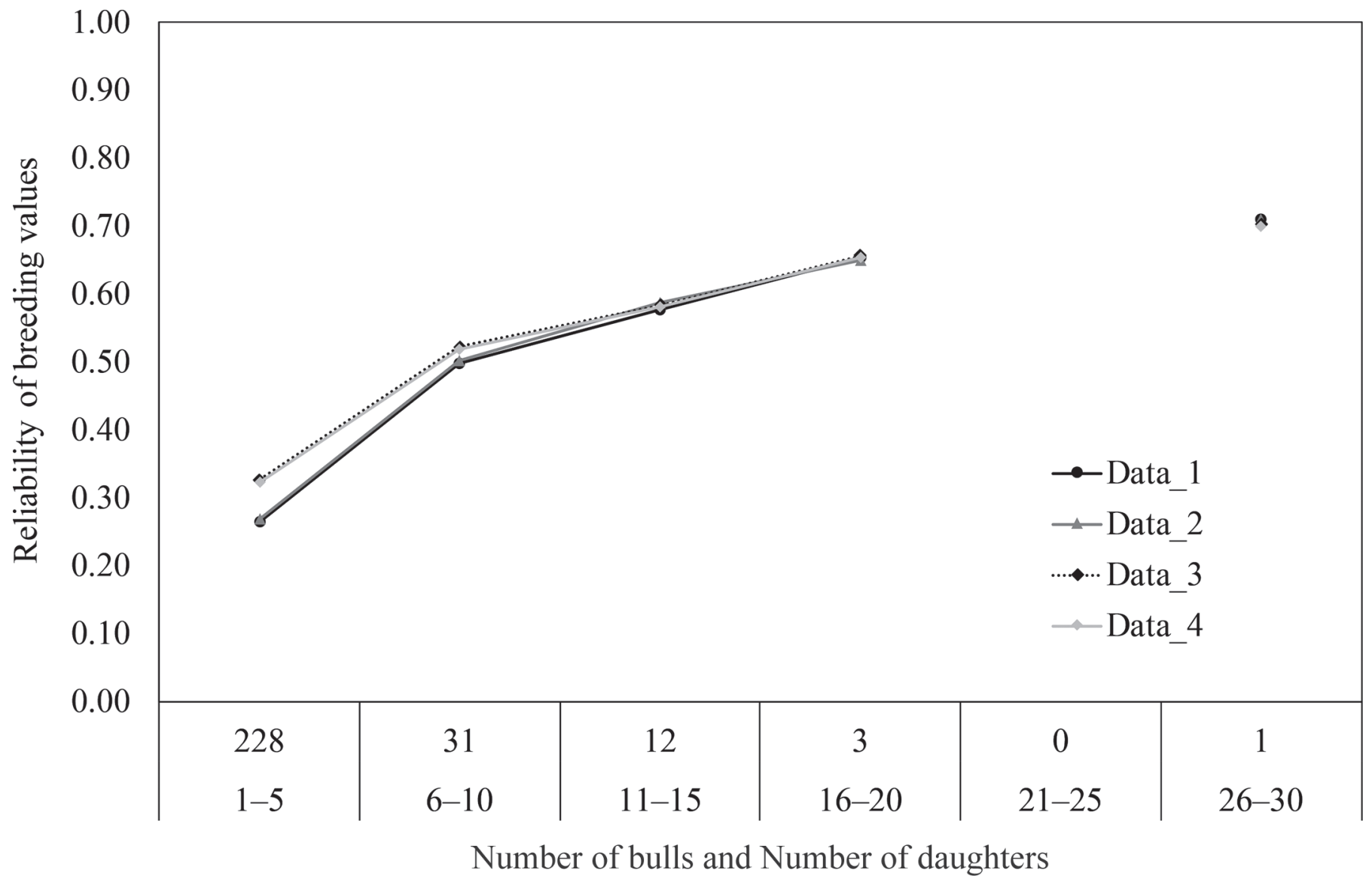

Figure 7. Realized reliabilities of bull breeding values for feed intake out of the 4 data sets: Data_1 (consists of all cows of the optiKuh training population with pedigree relationships only), Data_2 (consists of all cows of the optiKuh training population with both pedigree and genomic relationships), Data_3 (data set augmented with genotyped sires and dam sires), and Data_4 (data set augmented with sons of sires). On the $\mathrm{X}$ axis the numbers in the upper row show the number of bulls; the bottom row shows number of daughters. 
declined later on. Nevertheless, the moderate heritabilities for FI and EB are promising for implementation of genomic selection tools for both traits.

In the present study, genetic correlations estimated for the traits between different lactation stages are in line with other studies (Berry et al., 2007; Hüttmann et al., 2009). Our results strongly suggest that FI and EB in early estimates (20 DIM) are weakly correlated with estimates in late lactation (330 DIM), with values for FI at 0.23 (Data_2) and 0.08 (Data_1) and for EB at 0.08 and 0.18 , respectively. Only a few other studies were able to use the entire lactation for analyses (Liinamo et al., 2012; Li et al., 2018), but these also report the same properties of genetic correlation across DIM. For EB, Krattenmacher et al. (2019) found genetic correlations between early and mid-lactation at 0.37 . This is in contrast to the present results, where values between DIM 10 and DIM 180 tend to be lower at 0.03 , which is in close agreement with the results of Liinamo et al. (2012).
The pattern of genetic correlations across lactation indicates that FI and EB have a different genetic background at different DIM. This is underlined by the results of the GWAS of Tetens et al. (2014), which suggest that different genome regions affect FI over the course of lactation. The correlation between FI and EB breeding values of 0.63 in the study of Tetens et al. (2014) confirms that FI and EB are different traits but are correlated (Buttchereit et al., 2011), due to the fact that the calculation of EB includes FI measurements.

To define a breeding goal of reducing energy deficit at the beginning of lactation, one must first consider which trait, FI or EB, should be used. One must thus note that calculation of $\mathrm{EB}$ requires more data than does FI, including information on MY, milk ingredients, gestation stage, and body weight. The genetic correlations offer a possibility to increase FI or EB at the beginning of lactation, together with a minor increase of these traits at the end of lactation. So, in this lactation stage, extreme high body condition scores are

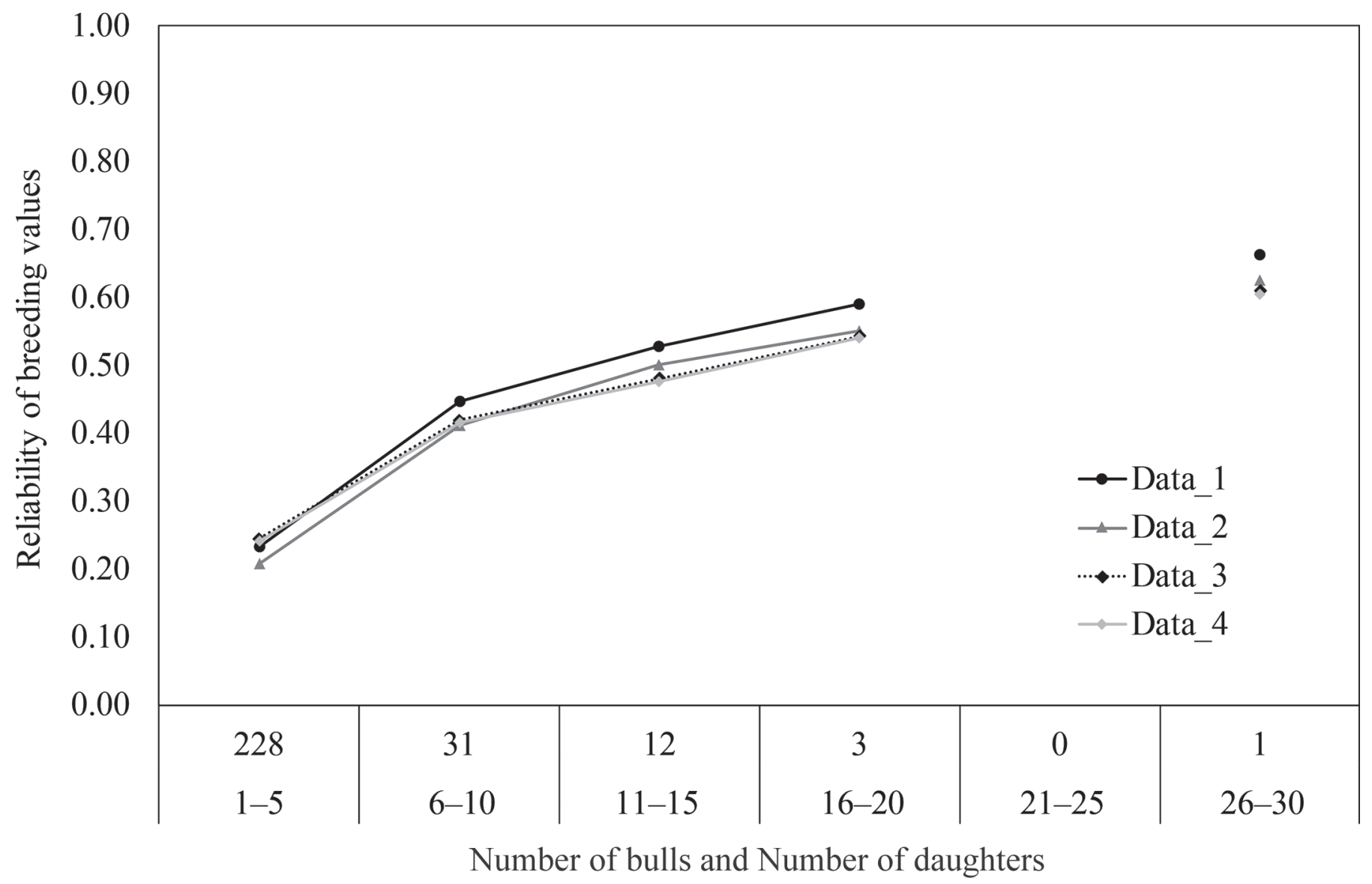

Figure 8. Realized reliabilities of bull breeding values for energy balance out of the 4 data sets: Data_1 (consists of all cows of the optiKuh training population with pedigree relationships only), Data_2 (consists of all cows of the optiKuh training population with both pedigree and genomic relationships), Data_3 (data set augmented with genotyped sires and dam sires), and Data_4 (data set augmented with sons of sires). On the $\mathrm{X}$ axis the numbers in the upper row show the number of bulls; the bottom row shows number of daughters. 
unlikely. Especially at the beginning of lactation, a high FI or a low energy deficit is required, to reduce risks of health problems that predominantly occur in this stage of lactation. An FI-dependent management strategy could help to avoid overconditioned cows by means of less - or, rather, demand-driven - food supply in the second half of lactation (Lin et al., 2013). A possible breeding strategy is to choose sires with high breeding values for $\mathrm{FI}$ at the beginning and low breeding values at the end of lactation.

Selection on higher FI or EB seems to be contrary to the general idea of an efficient cow. Feed efficiency can be characterized by gross efficiency (output/input relations) or by residual feed intake (RFI). Thus, RFI has been suggested as an important new trait, since feed accounts for the largest proportion of operating costs in dairy production (Connor, 2015; ManzanillaPech et al., 2016). Defined as the difference between energy intake and demand, RFI is usually estimated as the residuals from a model regressing FI on the various energy sinks, and it shows independence from the independent variables (Berry and Crowley, 2013;
Berry and Pryce, 2014). Efficient cows eat less than predicted, resulting in a negative RFI. Due to using nearly the same traits for calculation, EB and RFI are mathematically very similar (Savietto et al., 2014). So, selection for higher EB, to realize fewer health and reproductive disorders, especially in the first part of lactation, conflicts with feed efficiency (a positive RFI is inefficient). Therefore, feed efficiency traits should absolutely consider the health and reproductive status of the cows, as Veerkamp et al. (2013) recommended for lifetime feed efficiency.

Before DMI or EB can be included in a breeding goal, reliable genetic correlations between these traits and health and reproductive traits must be estimated, to confirm the positive effects of reducing the energy deficit. Also the genetic relationship between EB and RFI should be analyzed. For this purpose a huge data set comprising DMI, EB, RFI, and accurate recorded diagnoses and treatments is necessary.

Independent of selection strategies envisaged, levels of heritabilities, genetic correlations, and the reliabilities of breeding values for the most relevant traits provide

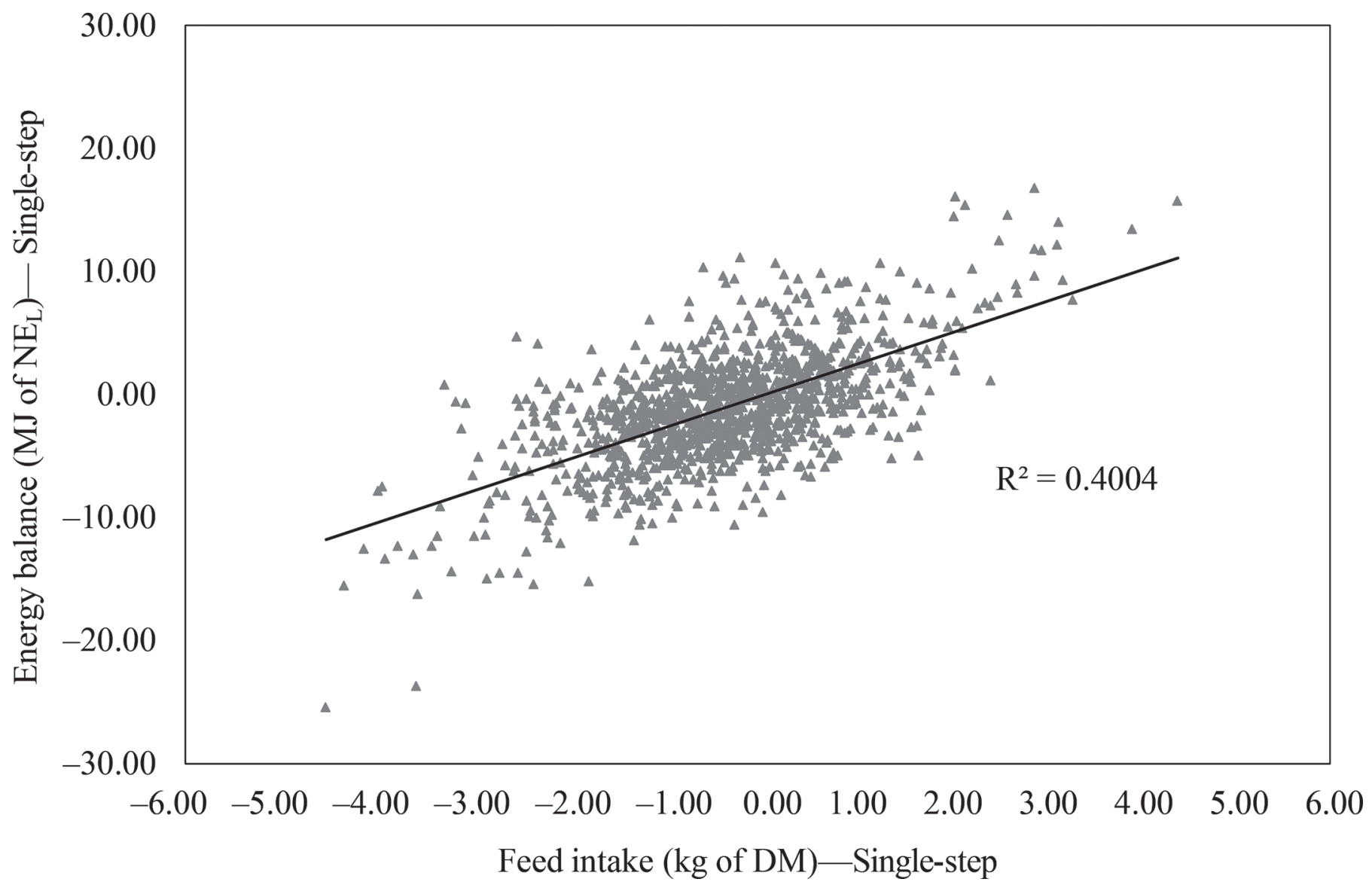

Figure 9. Scatter plot comparing mean breeding values of feed intake and energy balance (Data_2 set, all cows of the optiKuh training population with both pedigree and genomic relationships; 1,163 genotyped cows). 


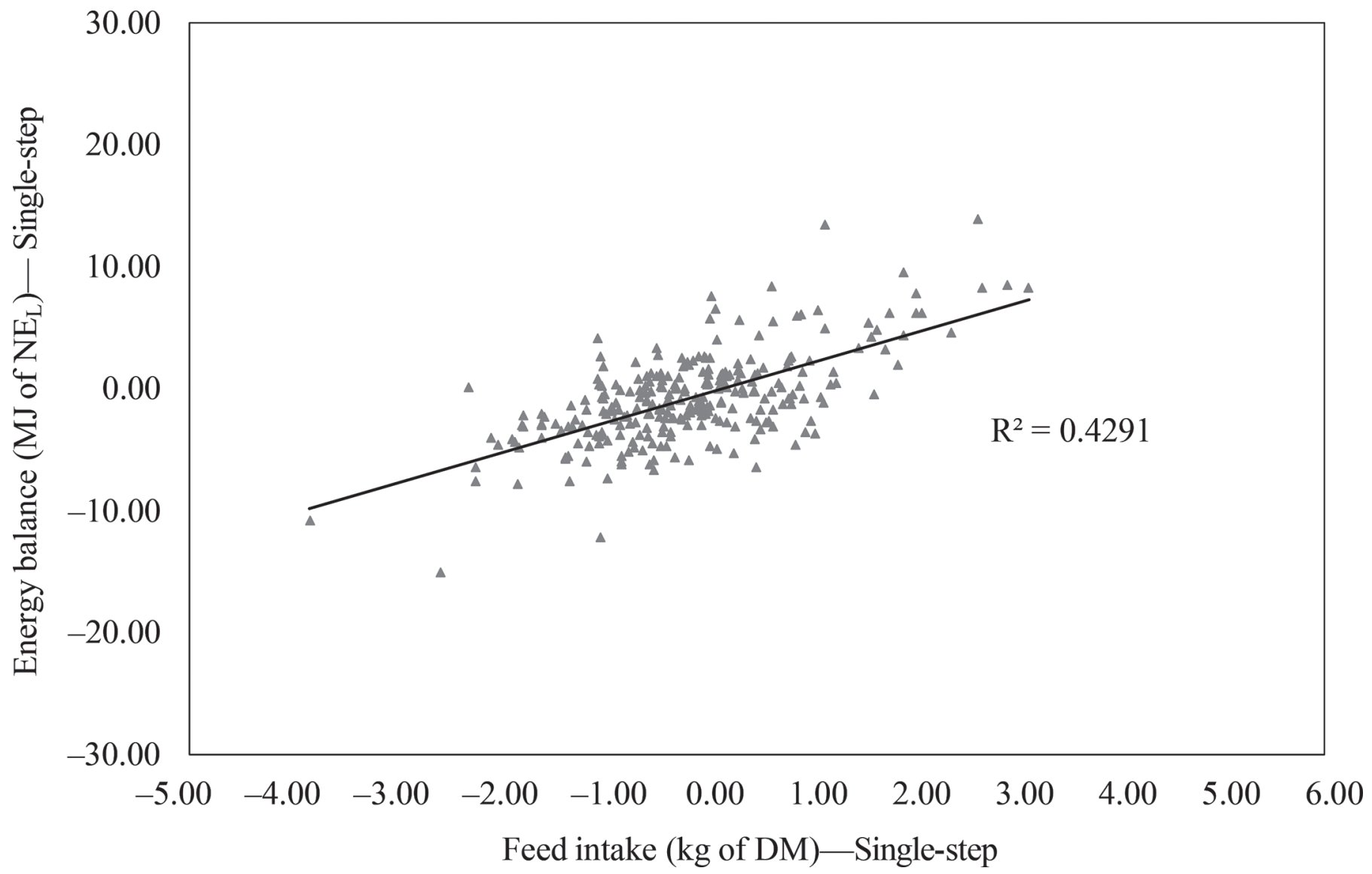

Figure 10. Scatter plot comparing mean breeding values of feed intake and energy balance (Data_2 set, all cows of the optiKuh training population with both pedigree and genomic relationships; 275 genotyped sires).

sufficient preconditions for genetic reduction of energy deficits at the beginning of lactation.

\section{CONCLUSIONS}

In the present study, the pedigree-based data set leads to higher reliabilities for animals with many phenotypic records compared with the single-step alternative. In contrast, by combining effectively phenotyped and genotyped animals using single-step genomic analytic procedures, relatively high reliabilities for unphenotyped but genotyped animals were achieved. In general, acceptable estimated breeding values could be generated, supporting selection for high FI or EB, to define a new breeding goal even for animals that have only been genotyped. Nevertheless, for more accurate breeding values, the reference population must be extended by both more phenotypes and more genotypes. Further steps, such as the use of ancillary traits, new options for measuring phenotypes, or establishing of economic weights, should be generated in order to finally implement these traits in the breeding goal of high-performing dairy cows.

\section{ACKNOWLEDGMENTS}

This project was supported by funds from the Federal Ministry of Food and Agriculture (BMEL; Bonn, Germany), based on a decision of the Parliament of the Federal Republic of Germany via the Federal Office for Agriculture and Food (BLE), under the Innovation Support Program.

\section{REFERENCES}

Aguilar, I., I. Misztal, D. L. Johnson, A. Legarra, S. Tsuruta, and T. J. Lawlor. 2010. Hot topic: A unified approach to utilize phenotypic, full pedigree, and genomic information for genetic evaluation of Holstein final score. J. Dairy Sci. 93:743-752. https://doi.org/10 $.3168 /$ jds.2009-2730.

Ali, T., and L. R. Schaeffer. 1987. Accounting for covariance among test day milk yields in dairy cows. Can. J. Anim. Sci. 67:637-644. https://doi.org/10.4141/cjas87-067.

Berry, D. P., M. P. Coffey, J. E. Pryce, Y. de Haas, P. Løvendahl, N. Krattenmacher, J. J. Crowley, Z. Wang, D. Spurlock, K. Weigel, 
K. Macdonald, and R. F. Veerkamp. 2014. International genetic evaluations for feed intake in dairy cattle through the collation of data from multiple sources. J. Dairy Sci. 97:3894-3905. https://doi .org/10.3168/jds.2013-7548.

Berry, D. P., and J. J. Crowley. 2013. Cell biology symposium: Genetics of feed efficiency in dairy and beef cattle. J. Anim. Sci. 91:1594-1613. https://doi.org/10.2527/jas.2012-5862.

Berry, D. P., B. Horan, M. O'Donovan, F. Buckley, E. Kennedy, M. McEvoy, and P. Dillon. 2007. Genetics of grass dry matter intake, energy balance, and digestibility in grazing Irish dairy cows. J. Dairy Sci. 90:4835-4845. https://doi.org/10.3168/jds.2007-0116.

Berry, D. P., and J. E. Pryce. 2014. Feed efficiency in growing and mature animals. In Proc. 10th World Congress of Genetics Applied to Livestock Production, Vancouver, BC, Canada.

Brotherstone, S., I. M. S. White, and K. Meyer. 2000. Genetic modelling of daily milk yield using orthogonal polynomials and parametric curves. Anim. Sci. 70:407-415. https://doi.org/10.1017/ S1357729800051754.

Buttchereit, N., E. Stamer, W. Junge, and G. Thaller. 2011. Short communication: Genetic relationships among daily energy balance, feed intake, body condition score, and fat to protein ratio of milk in dairy cows. J. Dairy Sci. 94:1586-1591. https://doi.org/10 $.3168 /$ jds.2010-3396.

Christensen, O. F., and M. S. Lund. 2010. Genomic prediction when some animals are not genotyped. Genet. Sel. Evol. 42:2. https:// doi.org/10.1186/1297-9686-42-2.

Coffey, M. P., G. C. Emmans, and S. Brotherstone. 2001. Genetic evaluation of dairy bulls for energy balance traits using random regression. Anim. Sci. 73:29-40. https://doi.org/10.1017/ S1357729800058021.

Coffey, M. P., G. Simm, and S. Brotherstone. 2002. Energy balance profiles for the first three lactations of dairy cows estimated using random regression. J. Dairy Sci. 85:2669-2678. https://doi.org/10 .3168/jds.S0022-0302(02)74352-X.

Connor, E. E. 2015. Invited review: Improving feed efficiency in dairy production: Challenges and possibilities. Animal 9:395-408. https: //doi.org/10.1017/S1751731114002997.

Cunningham, J. M., T. A. Sellers, J. M. Schildkraut, Z. S. Fredericksen, R. A. Vierkant, L. E. Kelemen, M. Gadre, C. M. Phelan, Y. Huang, J. G. Meyer, V. S. Pankratz, and E. L. Goode. 2008. Performance of amplified DNA in an Illumina GoldenGate BeadArray assay. Cancer Epidemiol. Biomarkers Prev. 17:1781-1789. https:// doi.org/10.1158/1055-9965.EPI-07-2849.

Daetwyler, H. D., R. Pong-Wong, B. Villanueva, and J. A. Woolliams. 2010. The impact of genetic architecture on genome-wide evaluation methods. Genetics 185:1021-1031. https://doi.org/10.1534/ genetics.110.116855.

de Haas, Y., J. E. Pryce, M. P. L. Calus, E. Wall, D. P. Berry, P. Lovendahl, N. Krattenmacher, F. Miglior, K. Weigel, D. Spurlock, K. A. Macdonald, B. Hulsegge, and R. F. Veerkamp. 2015. Genomic prediction of dry matter intake in dairy cattle from an international data set consisting of research herds in Europe, North America, and Australasia. J. Dairy Sci. 98:6522-6534. https://doi .org $/ 10.3168 /$ jds.2014-9257.

de Vries, M. J., and R. F. Veerkamp. 2000. Energy balance of dairy cattle in relation to milk production variables and fertility. J. Dairy Sci. 83:62-69. https://doi.org/10.3168/jds.S0022-0302(00)74856-9.

Edriss, V., B. Guldbrandtsen, M. S. Lund, and G. Su. 2013. Criteria of GenCall score to edit marker data and methods to handle missing markers have an influence on accuracy of genomic predictions. Arch. Tierzucht 56:778-788. https://doi.org/10.7482/0003-9438 $-56-077$.

Goddard, M. E., and B. J. Hayes. 2009. Mapping genes for complex traits in domestic animals and their use in breeding programmes. Nat. Rev. Genet. 10:381-391. https://doi.org/10.1038/nrg2575.

Guarini, A. R., D. A. L. Lourenco, L. F. Brito, M. Sargolzaei, C. F. Baes, F. Miglior, I. Misztal, and F. S. Schenkel. 2018. Comparison of genomic predictions for lowly heritable traits using multi-step and single-step genomic best linear unbiased predictor in Holstein cattle. J. Dairy Sci. 101:8076-8086. https://doi.org/10.3168/jds .2017-14193.
Harder, I., E. Stamer, W. Junge, and G. Thaller. 2019. Lactation curves and model evaluation for feed intake and energy balance in dairy cows. J. Dairy Sci. 102:7204-7216. https://doi.org/10.3168/ jds.2018-15300.

Heringstad, B., G. Klemetsdal, and J. Ruane. 2000. Selection for mastitis resistance in dairy cattle: A review with focus on the situation in the Nordic countries. Livest. Prod. Sci. 64:95-106. https://doi .org/10.1016/S0301-6226(99)00128-1.

Hüttmann, H., E. Stamer, W. Junge, G. Thaller, and E. Kalm. 2009. Analysis of feed intake and energy balance of high-yielding first lactating Holstein cows with fixed and random regression models. Animal 3:181-188. https://doi.org/10.1017/S175173110800325X.

Illumina Inc. 2005. Illumina GenCall Data Analysis Software. Illumina Inc., San Diego, CA.

Krattenmacher, N., G. Thaller, and J. Tetens. 2019. Analysis of the genetic architecture of energy balance and its major determinants dry matter intake and energy-corrected milk yield in primiparous Holstein cows. J. Dairy Sci. 102:3241-3253. https://doi.org/10 $.3168 /$ jds.2018-15480.

Legarra, A., I. Aguilar, and I. Misztal. 2009. A relationship matrix including full pedigree and genomic information. J. Dairy Sci. 92:4656-4663. https://doi.org/10.3168/jds.2009-2061.

Legarra, A., O. F. Christensen, I. Aguilar, and I. Misztal. 2014. Single Step, a general approach for genomic selection. Livest. Sci. 166:5465. https://doi.org/10.1016/j.livsci.2014.04.029.

Li, B., W. F. Fikse, P. Løvendahl, J. Lassen, M. H. Lidauer, P. Mäntysaari, and B. Berglund. 2018. Genetic heterogeneity of feed intake, energy-corrected milk, and body weight across lactation in primiparous Holstein, Nordic Red, and Jersey cows. J. Dairy Sci 101:10011-10021. https://doi.org/10.3168/jds.2018-14611.

Liinamo, A.-E., P. Mäntysaari, and E. A. Mäntysaari. 2012. Short communication: Genetic parameters for feed intake, production, and extent of negative energy balance in Nordic Red dairy cattle. J. Dairy Sci. 95:6788-6794. https://doi.org/10.3168/jds.2012-5342.

Lin, Z., I. Macleod, and J. E. Pryce. 2013. Short communication: Estimation of genetic parameters for residual feed intake and feeding behavior traits in dairy heifers. J. Dairy Sci. 96:2654-2656. https: //doi.org/10.3168/jds.2012-6134.

Madsen, P., J. Jensen, Labouriau R., L. G. Christensen, and G. Sahana. 2013. DMU-A package for analyzing multivariate mixed models in quantitative genetics and genomics. In Proc. 10th World Congress of Genetics Applied to Livestock Production, Vancouver, BC, Canada.

Mäntysaari, P., A.-E. Liinamo, and E. A. Mäntysaari. 2012. Energy efficiency and its relationship with milk, body, and intake traits and energy status among primiparous Nordic Red dairy cattle. J. Dairy Sci. 95:3200-3211. https://doi.org/10.3168/jds.2011-4685.

Manzanilla Pech, C. I. V., R. F. Veerkamp, M. P. L. Calus, R. Zom, A. van Knegsel, J. E. Pryce, and Y. de Haas. 2014. Genetic parameters across lactation for feed intake, fat- and protein-corrected milk, and liveweight in first-parity Holstein cattle. J. Dairy Sci. 97:5851-5862. https://doi.org/10.3168/jds.2014-8165.

Manzanilla-Pech, C. I. V., R. F. Veerkamp, Y. de Haas, M. P. L. Calus, and J. ten Napel. 2017. Accuracies of breeding values for dry matter intake using nongenotyped animals and predictor traits in different lactations. J. Dairy Sci. 100:9103-9114. https://doi.org/ $10.3168 /$ jds.2017-12741.

Manzanilla-Pech, C. I. V., R. F. Veerkamp, R. J. Tempelman, M. L. van Pelt, K. A. Weigel, M. VandeHaar, T. J. Lawlor, D. M. Spurlock, L. E. Armentano, C. R. Staples, M. Hanigan, and Y. de Haas. 2016. Genetic parameters between feed-intake-related traits and conformation in 2 separate dairy populations - the Netherlands and United States. J. Dairy Sci. 99:443-457. https://doi.org/10 .3168/jds.2015-9727.

Meuwissen, T. H. E., B. J. Hayes, and M. E. Goddard. 2001. Prediction of total genetic value using genome-wide dense marker maps. Genetics.157:1819-1829.

Muir, W. M. 2007. Comparison of genomic and traditional BLUPestimated breeding value accuracy and selection response under alternative trait and genomic parameters. Journal of animal breed- 
ing and genetics. J. Anim. Breed. Genet. 124:342-355. https://doi .org/10.1111/j.1439-0388.2007.00700.x.

Oltenacu, P. A., and D. M. Broom. 2010. The impact of genetic selection for increased milk yield on the welfare of dairy cows. Anim. Welf. 19(Suppl.):39-49.

Přibyl, J., J. Bauer, V. Čermák, P. Pešek, J. Přibylová, J. Šplíchal, H. Vostrá-Vydrová, L. Vostrý, and L. Zavadilová. 2015. Domestic estimated breeding values and genomic enhanced breeding values of bulls in comparison with their foreign genomic enhanced breeding values. Animal 9:1635-1642. https://doi.org/10.1017/ S1751731115001044.

Pryce, J. E., W. J. Wales, Y. de Haas, R. F. Veerkamp, and B. J. Hayes. 2014. Genomic selection for feed efficiency in dairy cattle. Animal 8:1-10. https://doi.org/10.1017/S1751731113001687.

Pszczola, M., K. F. Stock, E. Mucha, and E. Sell-Kubiak. 2018. Genetic architecture of methane emissions from dairy cows. In Proc. 11th World Congress of Genetics Applied to Livestock Production, Auckland, NZ.

Pszczola, M., T. Strabel, J. A. M. Van Arendonk, and M. P. L. Calus. 2012. The impact of genotyping different groups of animals on accuracy when moving from traditional to genomic selection. J. Dairy Sci. 95:5412-5421. https://doi.org/10.3168/jds.2012-5550.

Pszczola, M., R. F. Veerkamp, Y. de Haas, E. Wall, T. Strabel, and M. P. L. Calus. 2013. Effect of predictor traits on accuracy of genomic breeding values for feed intake based on a limited cow reference population. Animal 7:1759-1768. https://doi.org/10.1017/ S175173111300150X.

Randhawa, S. N. S., R. Ranjan, R. Singh, and N. Chand. 2014. Diagnosis and management of negative energy balance and associated production diseases in bovines. Intas Polivet 15:497-503.

Rauw, W. M., E. Kanis, E. N. Noordhuizen-Stassen, and F. J. Grommers. 1998. Undesirable side effects of selection for high production efficiency in farm animals: A review. Livest. Prod. Sci. 56:1533. https://doi.org/10.1016/S0301-6226(98)00147-X.

Reist, M., D. Erdin, D. von Euw, K. Tschuemperlin, H. Leuenberger, Y. Chilliard, H. M. Hammon, C. Morel, C. Philipona, Y. Zbinden, N. Kuenzi, and J. W. Blum. 2002. Estimation of energy balance at the individual and herd level using blood and milk traits in highyielding dairy cows. J. Dairy Sci. 85:3314-3327. https://doi.org/10 .3168/jds.S0022-0302(02)74420-2.

SAS. 2012. SAS 9.2 TS Level 1 M0. SAS Institute Inc., Cary, NC.

Savietto, D., D. P. Berry, and N. C. Friggens. 2014. Towards an improved estimation of the biological components of residual feed intake in growing cattle. J. Anim. Sci. 92:467-476. https://doi.org/ 10.2527 /jas.2013-6894.

Spurlock, D. M., J. C. M. Dekkers, R. Fernando, D. A. Koltes, and A. Wolc. 2012. Genetic parameters for energy balance, feed efficiency, and related traits in Holstein cattle. J. Dairy Sci. 95:5393-5402. https://doi.org/10.3168/jds.2012-5407.

Tetens, J., G. Thaller, and N. Krattenmacher. 2014. Genetic and genomic dissection of dry matter intake at different lactation stages in primiparous Holstein cows. J. Dairy Sci. 97:520-531. https://doi .org/10.3168/jds.2013-7301.

Vallimont, J. E., C. D. Dechow, J. M. Daubert, M. W. Dekleva, J. W. Blum, C. M. Barlieb, W. Liu, G. A. Varga, A. J. Heinrichs, and C. R. Baumrucker. 2011. Heritability of gross feed efficiency and associations with yield, intake, residual intake, body weight, and body condition score in 11 commercial Pennsylvania tie stalls. J. Dairy Sci. 94:2108-2113. https://doi.org/10.3168/jds.2010-3888.

Van Arendonk, J. A. M., G. J. Nieuwhof, H. Vos, and S. Korver. 1991. Genetic aspects of feed intake and efficiency in lactating dairy heifers. Livest. Prod. Sci. 29:263-275. https://doi.org/10.1016/0301 $-6226(91) 90103-W$.

VanRaden, P. M. 2008. Efficient methods to compute genomic predictions. J. Dairy Sci. 91:4414-4423. https://doi.org/10.3168/jds .2007-0980.

Veerkamp, R. F. 1998. Selection for economic efficiency of dairy cattle using information on live weight and feed intake: A review. J. Dairy Sci. 81:1109-1119. https://doi.org/10.3168/jds.S0022 -0302(98)75673-5.

Veerkamp, R. F., M. P. Coffey, D. P. Berry, Y. de Haas, E. Strandberg, H. Bovenhuis, M. P. L. Calus, and E. Wall. 2012. Genome-wide associations for feed utilisation complex in primiparous HolsteinFriesian dairy cows from experimental research herds in four European countries. Animal 6:1738-1749. https://doi.org/10.1017/ S1751731112001152.

Veerkamp, R. F., and E. P. C. Koenen. 1999. Genetics of food intake, live weight, condition score and energy balance. British Society of Animal Science Occasional Publication No. 24:63-73.

Veerkamp, R. F., J. E. Pryce, D. Spurlock, D. P. Berry, M. P. Coffey, P. Løvendahl, R. d. van Linde, J. Bryant, F. Miglior, Z. Wang, M. Winters, N. Krattenmacher, N. Charfeddine, J. Pedersen, and Y. de Haas. 2013. Selection on feed intake of feed efficiency: A position paper from gDMI breeding goal discussion. Interbull Bull. $47: 15-22$.

Veerkamp, R. F., and R. Thompson. 1999. A covariance function for feed intake, live weight, and milk yield estimated using a random regression model. J. Dairy Sci. 82:1565-1573. https://doi.org/10 .3168/jds.S0022-0302(99)75384-1.

von Leesen, R., J. Tetens, E. Stamer, W. Junge, G. Thaller, and N. Krattenmacher. 2014. Effect of genetic merit for energy balance on luteal activity and subsequent reproductive performance in primiparous Holstein-Friesian cows. J. Dairy Sci. 97:1128-1138. https://doi.org/10.3168/jds.2013-7185.

Wallén, S. E., M. Lillehammer, and T. H. E. Meuwissen. 2017. Strategies for implementing genomic selection for feed efficiency in dairy cattle breeding schemes. J. Dairy Sci. 100:6327-6336. https://doi .org/10.3168/jds.2016-11458.

Yokoyama, J. S., C. A. Erdman, and S. P. Hamilton. 2010. Arraybased whole-genome survey of dog saliva DNA yields high quality SNP data. PLoS One 5:e10809. https://doi.org/10.1371/journal .pone.0010809.

Zambrano, A. J., F. J. Rincón, H. A. López, and Z. J. Echeverri. 2015. Estimation and comparison of conventional and genomic breeding values in Holstein cattle of Antioquia, Colombia. Rev. Mvz Cordoba 20:4739-4753. https://doi.org/10.21897/rmvz.44.

\section{ORCIDS}

I. Harder (ํ) https://orcid.org/0000-0003-4631-856X 